\title{
Spoken Language Outcomes After Hemispherectomy: Factoring in Etiology
}

\author{
Susan Curtiss, \\ Stella de Bode \\ Department of Linguistics, Neuro/Psycholinguistics Laboratory, \\ University of California, Los Angeles, \\ and \\ Gary W. Mathern \\ Division of Neurosurgery, Brain Research Institute, Mental Retardation Research Center, \\ UCLA Medical Center \\ University of California, Los Angeles
}

Running head: Spoken Language After Hemispherectomy

We gratefully acknowledge the participation and courage of all of the children in this study and their families. We would also like to thank Prabha Siddarth for her gracious assistance with the statistical analyses. Correspondence concerning this article should be addressed to Susan Curtiss, Neuro/Psycholinguistics Laboratory, Department of Linguistics, 405 Hilgard Ave., UCLA, CA 90095-154302; scurtiss@ ucla.edu 


\begin{abstract}
We analyzed post-surgery linguistic outcomes of 43 hemispherectomy patients operated on at UCLA. We rated spoken language (Spoken Language Rank, SLR) on a scale from 0 (no language) to 6 (mature grammar), and examined the effects of side of resection damage, age at surgery/seizure onset, seizure control post-surgery, and etiology on language development. Etiology was defined as developmental (cortical dysplasia and pre-natal stroke) and acquired pathology (Rasmussen's encephalitis and post-natal stroke). We found that clinical variables were predictive of language outcomes only when they were considered within distinct etiology groups. Specifically, children with developmental etiologies had lower SLRs than those with acquired pathologies ( $\mathrm{p}=0.0006$ ); age factors positively correlated with higher SLRs only for children with acquired etiologies ( $\mathrm{p}=0.0006)$; right sided resections led to higher SLRs only for the acquired group ( $\mathrm{p}=$ 0.0008); and post-surgery seizure control positively correlated with SLR only for those with developmental etiologies ( $\mathrm{p}=0.0047)$. We argue that the variables considered are not independent predictors of spoken language outcome post-hemispherectomy but should be viewed instead as characteristics of etiology.
\end{abstract}

Key Words: language, hemispherectomy, epilepsy, developmental/acquired pathology 


\section{O. INTRODUCTION}

The overarching goal of our research program is to determine the linguistic capacity of each developing hemisphere after hemispherectomy. Little is understood about the mechanisms responsible for inter- vs. intra-hemispheric language transfer, thus, the potential of either hemisphere, alone, to serve as the substrate for the acquisition of grammar may not be adequately determinable by studies of focal damage or lesions in children (de Bode, 1998; Duchowny et al., 1996;

Helmstaedter, Kurthen, Linke, \& Elger, 1994; Papanicolaou, DiScenna, Gillespie, \& Aram, 1990). It is often unknown whether impaired linguistic performance in cases with focal lesions reflects the best efforts of the damaged $\mathrm{LH}$, the performance of the right hemisphere (RH), or some combination of both. Moreover, it has been suggested that reorganization after focal brain lesions in children may differ from that in adults (Papanicolaou et al., 1990). A main confound of focal lesion research is that location and extent of brain damage cannot be compared across studies; thus it is not surprising that findings regarding successful language transfer in children often conflict with each other (Levy \& Kave, 1999). Thus, in our opinion, it is the study of language development posthemispherectomy -- the removal of an entire cortical hemisphere -- that best addresses the question of the linguistic potential of each hemisphere.

There are comparatively few studies reporting language outcomes after hemispherectomy. Even though hemispherectomy in the treatment of intractable epilepsy began in the 1950's and 1960's (Griffith \& Davidson, 1966; Krynouw, 1950; McFie, 1961; Wilson, 1970), detailed studies of the effect of hemispherectomy on language appeared only in the 1970's (Dennis, 1976; Dennis \& Kohn, 1975; Dennis \& Whitaker, 1976; Gott, 1973; Smith \& Sugar, 1975). Although 333 cases 
of pediatric hemispherectomies have been reported worldwide (Holthausen, 1998) as of 1998, studies of the effects of hemispherectomy on language are limited to either case studies or small samples.

The current state-of-the-art, thus, still leaves us with a set of open questions regarding the capacity of each isolated developing hemisphere to acquire language: 1) what are the relevant "clinical" factors to examine (age at insult, age at surgery, side and extent of insult, seizure control, etc.); 2) what is the appropriate control group for children who have undergone hemispherectomy; ${ }^{1}$

3) how should language be assessed to determine whether there is successful or normal language acquisition or reacquisition following surgery? ${ }^{2}$ Each of these questions is key to a full understanding of the developmental patterns post- hemispherectomy. However, in this paper we concentrate on the first question: what factors are most predictive of linguistic outcome following hemispherectomy.

\section{LITERATURE REVIEW}

Examining the hemispherectomy research literature we find two major areas which call for further work. First, the literature is replete with inconsistent findings regarding post-surgery language outcomes. Second, contrary to research on focal brain lesions, hemispherectomy studies have not pursued the role of clinical variables on linguistic outcomes. These two problems are not independent: until we systematically factor in clinical variables on the effects of hemispherectomy on language, we will

\footnotetext{
${ }^{1}$ The question of control groups is an important one; however, at this juncture, having examined the literature and considered the question seriously, because of a number of confounding factors, our view is that there is no adequate control group for children who have undergone hemispherectomy.

${ }^{2}$ Although we do not address this question here, in our own population there is a striking contrast between performance on formal tests and performance in spontaneous speech, with the latter dramatically exceeding the former. We will be dealing with this question elsewhere; however, in our view, formal tests involve considerable cognitive and processing resources which make such tasks more than simply language tasks. Spontaneous speech, in contrast, seems to involve the fewest additional, nonlinguistic factors, thereby providing children with the optimal circumstance for linguistic performance. Also noteworthy, is the fact that many researchers do not even use tests
} 
not be able to make sense of relevant conflicts in the literature. Below we present examples from the hemispherectomy literature which illustrate this point.

\subsection{Recent literature on the age and side controversy}

Concerning brain recovery and age, the notion that the "earlier-the-better" concept originated with Kennard (Kennard, 1940), and was initially supported by animal research by others (Kolb, 1990; Villablanca, Carlson-Kuhta, Schmanke, \& Hovda, 1998). This widely accepted notion guided much of the research on focal lesions in humans (e.g., Teuber, 1975; Woods \& Teuber, 1978) and was automatically extended to hemispherectomy research as well (Vargha-Khadem \& Polkey, 1992). However, recent findings in studies of focal lesions and hemispherectomy (in humans and animals) challenge the assumption that the relationship between age and motor/cognitive recovery is monotonic (Bates, 1999a; Bates, Vicari, \& Trauner, 1999b; Eisele \& Aram, 1995; Reilly, Bates, \& Marchman, 1998; Vargha-Khadem, 1991; Villablanca \& Hovda, 2000).

Concerning the effect of side resected, the literature reports conflicting findings. There have been a number of studies reporting the greater capacity and proficiency of the left $(\mathrm{LH})$ over the right hemisphere $(\mathrm{RH})$ with respect to morphosyntactic comprehension, production, and judgments after hemispherectomy (Day \& Ulatowska, 1979; Dennis, 1980a; Dennis, 1980b; Dennis \& Kohn, 1975; Dennis \& Whitaker, 1976; Stark \& McGregor, 1997; Vargha-Khadem \& Polkey, 1992) and writing and spelling (Ogden, 1996). Others, (Ogden, 1988; Riva \& Gazzaniga, 1986; Vargha-Khadem et al., 1997a; Verity, 1982) have reported excellent, even normal linguistic abilities after hemispherectomy of either side. Ogden (1988), for example, reports on two adults who underwent left hemispherectomy as 
adolescents. On casual observation, language comprehension and spoken language appeared normal in both subjects. Specific deficits became evident only after specialized linguistic testing (tests of word fluency and Part 6 of the Token Test). Similarly, Alex, studied by Vargha-Khadem \& Mishkin, (1997) developed rich fluent speech, and linguistic deficits became evident again only through careful linguistic examination. Even more striking is the case documented by Mariotti et al. (Mariotti, Iuvone, Torrioli, \& Silveri, 1998). They tested a 20-year-old woman who had undergone left hemispherectomy at the age of 3 years. When formally tested, she performed at the level of IQ-matched controls (low normal levels of IQ) on all linguistic tasks. The tasks administered included grammaticality judgments, morphosyntactic comprehension (including active and passive constructions), and narrative comprehension tests. On tests of actives and passives (non-reversible and reversible) the subject showed some problems, but IQ controls made similar errors in these tasks.

In contrast to these studies, the five left hemispherectomized children examined by Stark and colleagues (Stark, Bleile, Brandt, Freeman, \& Vining, 1995) evidenced mixed language outcomes. One child performed extremely poorly, three children obtained scores at or below the $10^{\text {th }}$ percentile on the Test of Reception of Grammar (scores were based on mental age, MA), and the fourth child scored within the normal range for her chronological age, and above the expected level for her MA (post surgery follow-up 2;4-8 years). In contrast, three of the four right hemispherectomized children performed at their mental age levels on tests of syntactic comprehension.

Similarly, Stark and McGregor (Stark \& McGregor, 1997) report a five-year follow-up results on two children with Rasmussen's encephalitis who underwent hemispherectomies at age 4;0 and 5;8 years respectively. Despite the fact that both girls were well behind age-matched normals with respect to language performance, the left hemispherectomized child was especially impaired on tasks of 
morphosyntax. In contrast, the linguistic scores of the right hemispherectomized child were within her mental age range.

It is noteworthy that post surgery time in studies reporting the worse linguistic impairments tends to be shorter $(1-6$ years) in comparison to those reporting very minor or no language deficits $(16 ; 0$ 30;0 years). For example, in one of the most recent studies Boatman and colleagues (Boatman et al., 1999) looked at 6 children who underwent left hemispherectomy for treatment of Rasmussen's encephalitis. Language testing included speech sound discrimination, single word comprehension (a modified version of the Token test), repetition and naming. One year after surgery these children's comprehension (mostly of words) was comparable with normals, while spoken language development remained significantly compromised (single words and telegraphic speech). Hence, an examination of this literature illustrates that at this point it is neither clear whether children who undergo hemispherectomy can be expected to evidence good language development, nor under what circumstances such a prognosis will occur.

\subsection{Recent literature on Seizure Effects}

Given that hemispherectomy is performed in the treatment of intractable catastrophic epilepsy, it is important to consider the effect of post surgery seizure control and linguistic development in addition to side resected and age at surgery. Little research has been carried out specifically addressing the effects of post-surgery seizures on language (Dennis, 1988). There is no question that on-going seizure activity in children with and without surgery has a debilitating effect on all aspects of cognitive development, including language (Dulac, Pinard, \& Plouin, 1996; Isaacs, Chrisie, Vargha-Khadem, \& Mishkin, 1996; Muter, Taylor, \& Vargha-Khadem, 1997; O'Leary, 1983; Rossi et al., 1996; Vargha-Khadem, 1991). It is possible that on-going seizures affect language development similarly to overt focal lesions. For 
example, comparing the effect of left- versus right-temporal lobe seizures, Cohen (Cohen, 1992) reported the expected correlation between side and auditory/verbal vs. visual/spatial memory in children with complex partial epilepsy. Furthermore, specific aspects of linguistic performance (expressive versus receptive) were shown to be differentially affected in children with simple-partial left hemisphere epilepsy (Cohen \& Le Normand, 1998). Linguistic comprehension tested in this later study gradually improved to reach normal performance levels, while production remained quite poor in comparison with controls.

Later age at seizure onset has been associated with better language outcomes (Rossi et al., 1996). However, Vargha-Khadem (Vargha-Khadem \& Mishkin, 1997b) reports that both early and late onset of seizures have catastrophic effects on cognitive development. A general conclusion drawn from these and other studies (Dravet et al., 1996; Rossi et al., 1996) is that cognitive development in children with epilepsy is severely compromised in comparison with neurologically intact children, regardless of age of seizure onset.

It is thus surprising to find that the effect of seizure control in post-surgical patients and its relevance for cognitive and linguistic functions remains an area of great controversy. A few studies report that seizure-free patients perform no better cognitively than their counterparts who continue to have seizures after surgery (Grande et al., 1998; Seidel, Lin, Snead, \& Chen, 1998). However, post-surgical seizure control and linguistic outcome have not been specifically explored to our knowledge, though some reports suggest that this relation is far from linear (Bates et al., 1999b). Vargha-Khadem (1997a) reports that seizure control does not guarantee improved linguistic functioning in hemispherectomy patients. However, patients who become seizure-free after surgery performed early in life are sometimes asserted to demonstrate a better linguistic prognosis due to their brain reorganization. This is 
in contrast to children whose later onset of seizure disorder (Rasmussen's) is claimed to exclude any possibility of effective reorganization.

It is hard to establish the relationship between seizure activity and language outcomes since despite extensive research, the mechanism of seizures remains elusive. At present, it is not clear whether a lesion, itself, causes seizures, because in some cortical dysplasia (CD) patients many areas of cortical anomalies remain "silent", i.e. do not produce seizures (Metz-Lutz et al., 1999). Furthermore, the effect of seizures, including damage resulting from interictal activity (Rausch, Boone, \& Ary, 1991) and the potential disruption of healthy brain area development has not yet been positively established. Neither is it known how anticonvulsant medications influence the brain. Thus, the relationship between seizure activity and post surgery language outcome remains a challenging topic and it will be one of the areas investigated in this study.

\subsection{Recent literature on Age and Pathology}

While some researchers have pointed out the importance of studying etiology/pathological substrate in focal lesions (e.g., Dennis, 1988 \#219; Paquier \& Van Dongen, 1998), none has addressed the relationship between etiology and language outcome directly in hemispherectomy patients. Because etiology has always been considered secondary to factors such as age in the development of a function, conflicting results are reported. For example, Duchowny et al (Duchowny et al., 1996) claim that congenital lesions are worse for language than early acquired lesions, while Vargha-Khadem (VarghaKhadem \& Mishkin, 1997b) asserts that "perinatal" and early acquired pathologies (between 1 and 5 yrs.) result in better language outcomes than those occurring after the age of 5. Bates (1999a) states that infants with congenital pathology typically develop language within the normal range, in contrast to adults with lesions in the same regions. However, it should be noted that acquired lesions in adults, by 
definition, should not be directly compared to congenital lesions in infants, as such a comparison confounds the very differences imposed by the nature of these etiologies.

In the same vein, a few authors (Dennis, 1988; Vargha-Khadem, 1993) have raised the importance of the division between developmental and acquired pathologies. Dennis (1988) asserts that early, i.e. congenital and perinatal insults lead to "lagging" language development (later language emergence, "strategic detours" in the developmental course, and lagging rate of acquisition, but presumably normal language with respect to the ultimate linguistic system attained), while later onset of insult leads to linguistic deficits. ${ }^{3}$ Similar to Dennis, Vargha-Khadem (Vargha-Khadem, 1993) draws a distinction between developmental and acquired pathologies; however, her rationale is that developmental pathologies injure the brain before language has been established, whereas acquired pathologies disrupt functions either during their development or after they have been established. In the latter case, VarghaKhadem claims that lateralization and plasticity work against each other and attributes these as the mechanisms which define language outcome in acquired insults. However, it is not clear what mechanisms she would claim underlie recovery from developmental insult. Similar to Dennis and Vargha-Khadem many authors seem to confound age at seizure onset with differences in underlying pathologies.

Dennis and Vargha-Khadem frame their discussion in terms of language being a "skill", and in addition to disagreements we have concerning their consideration of etiology, we would disagree with their designation of language as a "skill". We would assert that language is a neurobiological function whose normal development reflects neurological and domain-specific cognitive maturation, rather than

\footnotetext{
${ }^{3}$ Moreover, Dennis compared early vascular malformations with later cerebral vascular accidents, claiming they produce similar brain damage commencing at different developmental periods. It is our belief, however, that different
} 
"skill" development, which is characterized by linear and hierarchical emergence, and is not part of the natural development of the species.

This literature overview illustrates the need to resolve the inconsistencies among studies, if we are ever to predict language outcomes post-hemispherectomy. We hypothesize that the conflicts can be explained once etiology is considered. We will argue that none of the other clinical factors - age, side of surgery, or seizure control - are independent predictors of language outcome. Rather, they are characteristics of etiology and should be considered within the context of etiology in predicting post surgery language outcome.

\section{STUDY DESIGN}

\section{$\underline{2.1 \text { Subjects }}$}

Our subject population consisted of 43 children who had undergone hemispherectomies as part of the UCLA Pediatric Epilepsy Surgery Program between 1986 and 1998 (Peacock et al., 1996). Patients were included in our sample if they had catastrophic childhood onset epilepsy, their seizures were resistant to antiepileptic medications, they had surgery before 18 years of age, they were monolingual speakers of Standard American English or were in a Standard American English environment, and they were patients for whom follow-up information was available. All subjects suffered from epilepsy with or without the syndrome of infantile spasms.

A breakdown of the subject population by side of damage, age at seizure onset, age at surgery, disease etiology, and gender is presented in Table 1.

\section{$\underline{2.2 \text { Methods }}$}

insult times/developmental periods are exactly the consequences of different etiologies, a point we will develop later 


\subsubsection{Etiology Classification.}

Each child's etiology was diagnosed on the basis of examination of their entire medical history, including pathology report, PET, MRI scans, video/EEG monitoring, seizure history, drug history, interictal and ictal scalp EEG, and assessment of neurodevelopment (Mathern et al., 1999). Each diagnosis was rated by a neurosurgeon and a pediatric neurologist blind to the rating of the first.

Etiology was catalogued according to the following breakdown:

- developmental pathology - 28 subjects (hemimegalencephaly - HM, cortical dysplasia/multilobar involvement - ML, and prenatal infarct);

- acquired pathology - 15 subjects (Rasmussen's encephalitis - RE and postnatal infarct)

\section{$\underline{\text { 2.2.2 Clinical Variables }}$}

Clinical variables were extracted from the medical records. These included age at seizure onset, age at surgery, post-surgical seizure control and side of resection. Seizure control was defined as "seizure-free" compared with residual seizures. Mean ages for all groups used in our data analyses are shown in Table 2.

Table 2. Mean Ages (in years) and Standard Deviations

\begin{tabular}{|l|c|c|c|c|c|}
\hline & $\begin{array}{c}\text { Entire Sample } \\
(43)\end{array}$ & Right (17) & Left (26) & $\begin{array}{c}\text { Develop } \\
\text { mental (28) }\end{array}$ & Acquired 15 \\
\hline $\begin{array}{l}\text { Age at seizure } \\
\text { onset }\end{array}$ & $1.53(2.55)$ & $1.67(2.81)$ & $1.44(2.42)$ & $0.21(0.29)$ & $4.08(3.05)$ \\
\hline Age at surgery & $4.33(4.01)$ & $4.16(4.67)$ & $4.40(3.58)$ & $2.51(2.43)$ & $7.76(4.26)$ \\
\hline
\end{tabular}

in our discussion. 


\begin{tabular}{|l|c|c|c|c|c|}
\hline $\begin{array}{l}\text { Follow-up } \\
\text { (from surgery to } \\
\text { last testing) }\end{array}$ & $6.13(3.11)$ & $6.43(2.39)$ & $5.92(3.55)$ & $6.33(3.04)$ & $5.74(3.3)$ \\
\hline
\end{tabular}

As seen from Table 2, the mean ages as well as the periods of follow-up for our right and left hemispherectomized groups were compatible across all parameters considered. However, there was a sharp distinction in mean age at seizure onset and surgery $(\mathrm{p}=0.0001)$ for the two pathology groups as previously reported (Mathern et al., 1999).

We expected that age at seizure onset and age at surgery would be highly correlated with each other and they were $(\mathrm{r}=0.799, \mathrm{p}=0.0001)$. We did data analyses using both variables and throughout this paper we will use both though age at seizure onset is our primary indicator (since seizures often is the first overt manifestation of the underlying pathology). Furthermore, each correlation reported is controlled for the period of follow-up (i.e. time elapsed from surgery to the point of data collection).

\subsubsection{Data Analysis}

Data were entered into a database and analyzed using a statistical program (SAS Software). Differences between clinical categories (i.e., right or left side, developmental or acquired, etc.) were statistically compared using an analysis of covariance (ANCOVA) controlling for the follow-up period. Other statistical tests included t-tests, and regression analyses. Results were considered significantly different at a minimum confidence level of $\mathrm{p}<0.05$.

\section{$\underline{\text { 2.3 Linguistic Evaluation }}$}

Because of the difficulty in establishing a common metric of comprehension across the full age range of children in this study, we concentrated on spontaneous language production. In 
addition, at the point of assessment, all of our subjects were of an age to be expected to talk in the course of normal language development (i.e., 3 years or older).

Postsurgical data on the children's language production were collected by means of the MacArthur Communicative Development Inventories (Fenson et al., 1990), or via language sampling, as developmentally appropriate or possible. A question specifically asking for speech onset age was added to the MacArthur for our use. Language samples were collected by means of the Story Game from the Kiddie Formal Thought Disorder Scales (Caplan, Guthrie, Fish, Tanguay, \& David-Lando, 1989) or via naturalistic conversation with the examiner interviewing the patient on topics including family, friends, school, birthday, TV shows, and favorite activities. These samples were recorded, transcribed and then analyzed for their grammatical and lexical content using CALC, a detailed grammatical analysis focusing on functional category structures, constituent structure and movement. At the time of testing we were blind as to the etiology of subjects. Each child's language sample was scored by two reviewers. Based on these data, we assigned each child a Spoken Language Rank (SLR), using a six-point scale, as shown in (1) below.

\section{(1) Spoken Language Ranks, (SLR):}

SLR=0, no language

SLR=1, a child has fewer than 20 words

$\mathbf{S L R}=\mathbf{2}$, a child has more than 20 words but no word combinations

$\mathbf{S L R}=3$, a child constructs short, telegraphic utterances and is in the so-called RI (Root Infinitive) stage. The RI stage refers to a developmental stage wherein a child uses nonfinite verb forms in root clauses; i.e., in contexts that clearly require a finite verb in the adult 
language. An RI stage in the acquisition of English and certain other languages (Hoekstra \& Hyams, 1998; Hyams, 1996) is attested to by the fact that children in many languages use infinitives where the adult languages do not allow it. (2) below, presents examples:

(2) Eve sit floor

Where penny go? $\quad$ (CHILDES, (Brown, 1973)

$\mathbf{S L R}=\mathbf{4}$, a child has developed beyond the telegraphic stage, and makes only occasional errors in the use of functional category elements, but shows no $\mathrm{CP}$ (complementiser phrase) embeddings. Following this definition, the C-system may be limited to inverted forms of be, have, do, will, shall and inverted modals. Elements of the I-system and D-system will be consistently found in transcripts of children with an SLR of 4, however. Transcripts of four children who received a ranking of " 4 " are currently being examined (de Bode, in preparation) to describe this stage of language development, which may or may not parallel language development under normal conditions.

$\mathbf{S L R}=\mathbf{5}$, a child has fluent speech plus embeddings of all types, and evidence of movement (Wh-questions, yes/no questions). Some "gaps" in morpho-syntax may persist, however (e.g. errors with the passive past participle), differentiating the grammar of a child with an SLR of 5 from a fully mature grammar.

$\mathbf{S L R}=6$, a child has a mature grammar.

Sometimes a child's score indicates an intermediate stage of her linguistic development (e.g. SLR=2.5).

\section{RESULTS}

Statistical analyses were performed in order to examine the relationship between SLR and age 
at seizure onset, age at surgery, side of surgery, seizure control, and etiology (developmental or acquired).

\section{$\underline{3.1 \text { Age Factors }}$}

\section{$\underline{\text { 3.1.1 Age and Etiology }}$}

For all t-tests both age at seizure onset $(\mathrm{p}=0.0022)$ and age at surgery $(\mathrm{p}=0.0018)$ positively correlated with SLR. However, examining by the etiology group as shown in Table 3, the correlation between age and SLR was statistically significant only for the acquired group $(p=0.0006$ for seizure onset, $p=0.044$ for age at surgery). Thus, we conclude that it was the correlation between age and the group with acquired pathology which drove the correlation between age and the group as a whole. Moreover, the acquired pathology group exhibited the robust direct relation between age factors and SLR, in that the older the child at seizure onset and surgery, the better the post surgery language outcome.

Table 3. Age and etiology

\begin{tabular}{|l|c|c|c|}
\hline $\begin{array}{c}\text { variable } \\
\text { population \& }\end{array}$ & Entire sample (43) & $\begin{array}{c}\text { Developmental } \\
(28)\end{array}$ & $\begin{array}{c}\text { Acquired } \\
(15)\end{array}$ \\
\hline $\begin{array}{c}\text { Age at seizure } \\
\text { onset }\end{array}$ & $0.0022(\mathrm{r}=0.396)$ & $0.7054(\mathrm{r}=0.05)$ & $0.0006(\mathrm{r}=0.240)$ \\
\hline Age at surgery & $0.0018(\mathrm{r}=0.396)$ & $0.4016(\mathrm{r}=0.121)$ & $0.044(\mathrm{r}=0.286)$ \\
\hline
\end{tabular}

These statistical results are our first indicator that etiology cannot be ignored in considering linguistic outcomes after hemispherectomy, and that our division of etiology into developmental and acquired is a fruitful one for examining the relationship between language development and the brain.

\subsubsection{Age and Side of Resection}


In addition, age variables were examined with respect to side of resection. Both age at seizure onset and age at surgery were significant predictors of language outcome, but only for the right hemispherectomies (Table 4). There was a statistically significant positive correlation between age at seizure onset and SLR, and age at surgery and SLR for the right hemispherectomies $(p=0.0009$, and $p$ $=0.003$, respectively), indicating again the older the child the better the spoken language outcome, whereas no significant findings were obtained between age factors and left hemispherectomies $(\mathrm{p}=0.4642$, and $\mathrm{p}=0.3957)$.

Table 4. Age and Side of Resection

\begin{tabular}{|c|c|c|c|}
\hline variable & $\begin{array}{c}\text { Entire } \\
\text { population \& } \\
\text { sample (43) }\end{array}$ & $\begin{array}{c}\text { Right } \\
\text { Resection } \\
(17)\end{array}$ & $\begin{array}{c}\text { Left } \\
\text { Resection } \\
(26)\end{array}$ \\
\hline $\begin{array}{c}\text { Age at seizure } \\
\text { onset }\end{array}$ & 0.0022 & 0.0009 & 0.4642 \\
\hline Age at surgery & 0.0018 & 0.003 & 0.3957 \\
\hline
\end{tabular}

This robust correlation between older age and better language outcome after right hemispherectomy is a result we have found consistently, since our earliest examination of this population. This is an expected finding, as later insults to the right hemisphere means that the left hemisphere has had a longer period in which to become instantiated as the neural base for language, and the right hemisphere will have had time to play its role in the early stages of language development.

\subsection{Side of Resection}


Side of surgery proved not to be a significant predictor of language outcome when we examine the subject population as a whole, $(\mathrm{p}=0.5969)$, even when controlled for age at onset/surgery (0.4083), or when controlled for post surgery seizure outcome (0.67). However, we did find that the side of surgery was a significant predictor of SLR for the acquired pathology group (0.0008), reflecting the fact that the isolated left hemisphere strongly outperformed the isolated right hemisphere. Even though the developmental pathology group showed a trend in this direction $(\mathrm{p}=0.08)$, we can conclude that the effect of side resected is determined primarily by the linguistic outcomes in the group with acquired pathology (see Table 5). The finding that the isolated left hemisphere outperforms the right in language is one we expected; however, once again, we see that etiology can interfere with establishment of the expected brain-language relation.

Table 5. Side of Resection

\begin{tabular}{|c|c|c|c|}
\hline & $\begin{array}{c}\text { Entire } \\
\text { sample (43) }\end{array}$ & $\begin{array}{c}\text { Development } \\
\text { al (28) }\end{array}$ & $\begin{array}{c}\text { Acquired } \\
(15)\end{array}$ \\
\hline $\begin{array}{c}\text { Side (Left or } \\
\text { Right) }\end{array}$ & 0.5969 & 0.08 & 0.0008 \\
\hline
\end{tabular}

\subsection{Seizure Control}

As illustrated in Table 6, there was a significant positive correlation between the group as a whole and post-surgical seizure control $(\mathrm{p}=0.0081)$. This effect becomes even stronger when we control for age factors and side of resection $(\mathrm{p}=0.0014)$. However, upon closer examination we found that this correlation was significant only for the developmental pathology group $(p=0.0047)$. There was no significant correlation between seizure control and SLR in the acquired pathology group $(\mathrm{p}=$ 0.9048). We interpret these results as another strong indication that the difference in etiology between 
these groups reflects a distinction critical for understanding the pattern of linguistic outcome following hemispherectomy.

Table 6. Seizure Control

\begin{tabular}{|c|c|c|c|}
\hline & $\begin{array}{c}\text { Entire } \\
\text { sample (43) }\end{array}$ & $\begin{array}{c}\text { Development } \\
\text { al (28) }\end{array}$ & $\begin{array}{c}\text { Acquired } \\
\text { (15) }\end{array}$ \\
\hline $\begin{array}{c}\text { Post-surgery } \\
\text { seizure control }\end{array}$ & 0.0081 & 0.0047 & 0.9048 \\
\hline
\end{tabular}

\subsection{Etiology}

Etiology (developmental or acquired) has consistently emerged as a significant variable distinguishing linguistic outcomes in all statistical analyses. To further establish that etiology was critical in determining language outcomes, we compared SLRs of both groups and found that SLR was highly dependent on etiology group ( $\mathrm{p}=0.0006$ ). In other words, children with developmental etiologies had mean SLRs $(S D)$ that were less than the acquired group (2.8 2.2 versus 5.0 0.9). Since by definition the two groups differ critically in ages of onset, in this analysis, age variables could not be controlled for. However, this dependency between etiology and SLR remained strong when controlled for seizure outcome $(\mathrm{p}=0.0007)$.

In addition, we hypothesized that spoken language outcomes would correlate with the type of pathology within each group. Our hypothesis was partially supported: for three etiologies (HM, ML and prenatal infarct) within the developmental pathology group, SLRs correlated with the type of pathology $(\mathrm{p}=0.025)$. However, no difference was found for the two subgroups within the acquired group ( $\mathrm{RE}$ and postnatal infarct, $\mathrm{p}=0.3591$ ). This suggests that more detailed examination of specific 
etiologies, beyond the developmental vs. acquired division is called for, a point we take up in the Discussion.

\subsection{Summary of Results}

In summary, we hypothesized that a number of factors predictive of language outcomes after hemispherectomy (e.g., age at seizure onset/surgery, side and seizure control) will prove to be dependent on etiology of epilepsy disorder. Our hypothesis was supported by the following findings (see Table 7).

Table 7. Summary of Results

\begin{tabular}{|c|c|c|c|c|c|}
\hline $\begin{array}{c}\text { Predictor of } \\
\text { SLR/ } \\
\text { population }\end{array}$ & $\begin{array}{c}\text { The entire } \\
\text { sample }\end{array}$ & Developm. & Acquired & Right & Left \\
\hline $\begin{array}{c}\text { Age at } \\
\text { seizure } \\
\text { onset or } \\
\text { surgery }\end{array}$ & predictive & not & predictive & $\begin{array}{c}\frac{\text { predictive }}{\text { (the older- }} \\
\text { the better) }\end{array}$ & predictive \\
\hline $\begin{array}{c}\text { Side of } \\
\text { resection } \\
\text { (isolated } \\
\text { Left } \\
\text { better) }\end{array}$ & predictive & predictive & predictive & n/a & n/a \\
\hline $\begin{array}{c}\text { Seizure } \\
\text { control }\end{array}$ & predictive & predictive & predictive & $\mathrm{n} / \mathrm{a}$ & $\mathrm{n} / \mathrm{a}$ \\
\hline
\end{tabular}

We found that age at seizure onset/surgery proved significant only for the acquired group.

When we examined the effect of side and SLR, we found that age proved significant only for the right hemispherectomies, in that the older the child, the better the language outcome. We also found that the isolated LH outperforms the isolated RH, but only for those with acquired pathology. Moreover, seizure control was predictive of SLR for the developmental but not the acquired group. Although "seizure 
control" was among variables predicting language outcome, it should be noted that it was not possible to accurately predict its effect in all patients, (i.e. some patients developed language despite ongoing seizures while others failed to develop language despite post-surgical seizure control). We are currently investigating this issue. In conclusion, however, we found that with respect to each clinical variable we examined, etiology proved to be the crucial factor for sorting out our significant findings.

\section{DISCUSSION}

When we started this research project 5 years ago, we held a set of assumptions based on the literature; specifically, we assumed that side of resection and age at seizure onset/surgery were the primary factors which would predict the extent and nature of language development following hemispherectomy. In keeping with tradition, we believed that left hemispherectomy would have greater negative impact on language acquisition than right hemispherectomy, and that the younger the child at age of insult, the better the prognosis.

However, our failure to find the expected correlations in our cohort, led us to question these underlying assumptions and to re-examine on a case-by-case basis which children either failed to develop language, or developed remarkably good spoken language. We started with two groups whose language outcomes most conspicuously challenged our expectations: 1) right hemispherectomies who remained mute, evidencing no language development in the left brain, and 2) left hemispherectomies with remarkably good linguistic development whose language developed well in the right brain.

As we explored our data, we noted that those children who fared the worst with respect to language shared a common etiology (namely, HM), which was different from the etiologies of children who did well (prenatal infarcts and Rasmussen's encephalitis). In other words, functional outcomes 
corresponded to particular etiologies. This discovery led us to focus on etiology in both our own cohort and in the literature. As a result of this pursuit, we found that considering etiology as a primary factor allowed us to sort out confusing results reported in the literature concerning the effects of age, side, and extent of lesion on language outcomes post hemispherectomy.

Our main finding, that children with developmental pathology showed lower SLRs than those with acquired pathology could be accounted for in two ways. First, age (age at insult and/or age at testing) could be the crucial underlying factor distinguishing the etiology groups and their ultimate performance, or second, the differing outcomes of the two groups could be a reflection of critical endogenous differences in etiologies.

While we continue to be open to both possibilities, we propose that it is the latter explanation that is best supported by the data, our own and that of other researchers. First, with respect to our own data, our follow up period is long enough (mean time from surgery to testing was 6 years) to directly address whether or not age is the critical factor generating the important differences in our findings. Second, both etiology groups we have studied were old enough at testing (older than 5 years) to have SLRs of 5 (fluent, essentially mature language), even though their mean ages were notably different (Developmental (8 yrs.) and Acquired (13 yrs). To verify our hypothesis, we are in the process of calculating Z-scores for our patients at each age level compared to the performance of age-matched normal controls. Because our SLRs are defined on the basis of stages in normal language development, we are in a position to carry out such a comparison ${ }^{4}$.

\footnotetext{
${ }^{4}$ It should be emphasized that our findings are relevant to patients with mostly unilateral symptomatic epilepsy that can be treated surgically. Our results may or may not reflect language development in patients with idiopathic or cryptogenic epilepsy that involve bilateral epileptogenic mechanisms.
} 
How will our proposal alter our understanding of the picture regarding language development following hemispherectomy or other significant brain insult? Reexamining the literature on successful language reorganization, one notices that it is age and extent of insult which are the factors examined and stressed by the authors (see (de Bode, 1998); yet relying on age and extent, researchers report findings which directly conflict with each other. However, on our account, these findings are no longer in conflict; they converge. Focusing on etiology will eliminate the need to separately examine age of insult, extent of insult and seizure history and will allow us to account for different language outcomes when these factors do not differ. Furthermore, it will eliminate the necessity to superimpose the developmental status of language and age at insult. The nature of the etiology determines the prospective or retrospective course of language development. Moreover, we suggest that the same recovery mechanisms will be at play, and different linguistic outcomes will reflect the different neurobiological substrates as determined by etiology.

Our point is further illustrated by examining research on two congenital etiologies with similar insult onset times; namely, Sturge-Weber (SW) syndrome and cortical dysplasia (CD). Despite the fact that both are prenatal developmental etiologies originating in the first trimester of pregnancy, comparing our own two cases of SW and those from the existing literature (e.g., Dennis, 1980a, b; VarghaKhadem et al, 1998; Mariotti, 1999) to our population with CD, we find markedly different outcomes. The remarkable linguistic outcomes of Alex (Vargha-Khadem and Mishkin, 1997), MP (Mariotti et al., 1998) and our own 2 SW cases, VI and SM, contrast sharply with the heterogeneous and often poor outcomes of the CD group. We propose that age and extent are actually epiphenomena of etiology and should be considered characteristics of etiology rather than independent of it. Note that we are not arguing that age is not to be considered at all; rather we are proposing that age is a dependent factor - 
defined by etiology. An example of this claim can be found in comparing functional outcomes of prenatal and postnatal infarct (de Bode, 2001). So what is left of the old story when we make etiology the primary factor to consider? Nowhere in our data was "the earlier-the-better" notion attested; however, it is still possible that within specific etiologies, this notion would hold. More importantly, though, in considering our findings, we entertain the possibility that the earlier-the-better notion cannot be applied within a pediatric group across etiologies. In other words, the "earlier-the better" hypothesis holds primarily for comparing pediatric populations to adult populations. We believe that our account will contribute to the current picture and debate on the issue of critical (or sensitive) periods in language acquisition in two ways. First, while we have drawn from the animal literature in our understanding of neurobiology, we do not believe that the issue of a critical period for language development can be driven by animal research or research on clinical populations, for two reasons. First, animal research ignores etiology, and second, animal research is carried out on healthy animals with a healthy remaining hemisphere. ${ }^{5}$ Therefore, cases such as Alex (Vargha-Khadem et al., 1997a), where overt language development began around 9 years of age, cannot be used to address the issue of how late first language acquisition can begin. It has also been noted in the literature that language outcomes are dependent on seizures (Isaacs et al., 1996; Vargha-Khadem \& Mishkin, 1997b). However, once again, on our account making etiology the primary factor, it becomes possible to view seizures as an integral part of the underlying pathology.

Our examination of etiology is the logical continuation of our previous research where we raised the importance of the point in development when the insult occurs. In what we had termed the "Critical Impact Point" hypothesis, we proposed that the point in both neurological and functional maturation at

\footnotetext{
${ }^{5}$ In addition, of course, to the fact that animals do not have language.
} 
which the insult is suffered will determine the subsequent outcome (Curtiss \& de Bode, 1999b). Our current results refine this hypothesis, in that we have found that the variable of etiology, itself, turns out to be the umbrella construct for age, extent and the mechanism of injury. On this explanation, etiology can account for the sequalae of developmental disruption. Introducing etiology into our hypothesis, then, will allow us to predict the different consequences we find, as each etiology affects pre or postnatal development in distinct ways.

Taking this turn in our research wherein we have focused on etiology rather than side, age, and extent of insult, has been a fruitful one. Once we made etiology our focus, we found we were able to provide a single account for a wide variety of conflicting results which were otherwise neither predicted nor explained, in our own research and in the field as a whole. This direction of research will lead us to continue to explore neurobiological factors in our goal of defining the relationship between functional recovery and underlying neurobiology. Specifically, our current research now addresses the status of the remaining hemisphere as a primary factor defining language outcome (de Bode, 2001; de Bode \& Curtiss, 2000) in accordance with previous suggestions in the literature (Vargha-Khadem \& Polkey, 1992; Verity, 1982). Through our research, then, we hope to make important contributions -- most specifically to our understanding of the relationship between language development, language recovery and the brain. 
$\underline{\text { Table 1. Subjects }}$

\begin{tabular}{|c|c|c|c|c|c|c|}
\hline \multirow[t]{2}{*}{ Patient/No } & $\begin{array}{l}\text { Side } \\
\text { 1-L, 2-R }\end{array}$ & DOB & $\begin{array}{l}\text { Age/onset } \\
\text { (years) }\end{array}$ & $\begin{array}{l}\text { Age/surgery } \\
\text { (years) }\end{array}$ & $\begin{array}{l}\text { Sz control } \\
\text { 1yes } 2 \text { no }\end{array}$ & $\begin{array}{l}\text { SLR } \\
\text { 1to } 6\end{array}$ \\
\hline & \multicolumn{6}{|c|}{ Hemimegalencephaly } \\
\hline $1 \mathrm{M}$ & 1 & $11 / 14 / 91$ & 0.05 & 2.83 & 1 & 4 \\
\hline $2 \mathrm{M}$ & 1 & $3 / 23 / 84$ & 0.08 & 3.33 & 2 & 0 \\
\hline $3 \mathrm{M}$ & 1 & $3 / 2 / 90$ & 0.01 & 0.25 & 1 & 0 \\
\hline $4 \mathrm{~F}$ & 2 & 9/1/93 & 0.5 & 2.58 & 2 & 1 \\
\hline $5 \mathrm{~F}$ & 2 & $12 / 5 / 93$ & 0.02 & 2.1 & 2 & 0 \\
\hline $6 \mathrm{~F}$ & 2 & 4/2/95 & 0.01 & 0.41 & 2 & 1 \\
\hline \multirow[t]{2}{*}{$7 \mathrm{M}$} & 2 & $3 / 22 / 89$ & 0.01 & 1.5 & 2 & 0 \\
\hline & & \multicolumn{5}{|c|}{ Cortical Dysplasia/Multilobar Involvement } \\
\hline $8 \mathrm{M}$ & 1 & $1 / 27 / 93$ & 0.5 & 1.63 & 1 & 3 \\
\hline $9 \mathrm{~F}$ & 1 & $9 / 12 / 91$ & 0.01 & 1.42 & 2 & 6 \\
\hline $10 \mathrm{M}$ & 1 & $2 / 21 / 91$ & 0.01 & 0.67 & 1 & 6 \\
\hline $11 \mathrm{M}$ & 1 & $9 / 23 / 84$ & 0.01 & 1.41 & 2 & 2 \\
\hline $12 \mathrm{M}$ & 1 & $3 / 2 / 94$ & 0.01 & 1 & 1 & 4 \\
\hline $13 \mathrm{M}$ & 1 & $12 / 5 / 90$ & 0.5 & 1.5 & 1 & 6 \\
\hline $14 \mathrm{~F}$ & 1 & 7/15/92 & 0.05 & 0.41 & 2 & 5 \\
\hline $15 \mathrm{M}$ & 1 & $2 / 14 / 88$ & 0.11 & 0.75 & 1 & 3 \\
\hline $16 \mathrm{~F}$ & 2 & $5 / 16 / 95$ & 0.01 & 0.33 & 2 & 3 \\
\hline $17 \mathrm{~F}$ & 2 & $1 / 14 / 93$ & 0.41 & 0.75 & 1 & 5 \\
\hline $18 \mathrm{~F}$ & 2 & $8 / 5 / 91$ & 0.01 & 1.1 & 2 & 2.5 \\
\hline \multirow[t]{2}{*}{$19 \mathrm{M}$} & 2 & $11 / 22 / 88$ & 0.75 & 3.8 & 2 & 1 \\
\hline & \multicolumn{6}{|c|}{ Rasmussen's Encephalitis } \\
\hline $20 \mathrm{M}$ & 1 & $2 / 12 / 92$ & 3.33 & 4.58 & 2 & 4 \\
\hline $21 \mathrm{M}$ & 1 & $8 / 30 / 90$ & 2.25 & 3.5 & 1 & 4 \\
\hline $22 \mathrm{M}$ & 1 & 8/16/89 & 2.91 & 5.95 & 2 & 3 \\
\hline $23 \mathrm{M}$ & 1 & $5 / 14 / 84$ & 10.33 & 12.75 & 1 & 5 \\
\hline $24 \mathrm{~F}$ & 1 & $6 / 3 / 88$ & 5 & 10 & 1 & 5 \\
\hline $25 \mathrm{~F}$ & 1 & $3 / 24 / 89$ & 5.5 & 6.91 & 2 & 5 \\
\hline $26 \mathrm{~F}$ & 2 & $7 / 22 / 83$ & 4.75 & 5.66 & 1 & 6 \\
\hline $27 \mathrm{~F}$ & 2 & $11 / 24 / 72$ & 4.18 & 14 & 2 & 6 \\
\hline $28 \mathrm{~F}$ & 2 & $10 / 11 / 74$ & 11 & 17.33 & 2 & 6 \\
\hline \multirow[t]{2}{*}{$29 \mathrm{M}$} & 2 & $11 / 4 / 87$ & 2.05 & 3.41 & 1 & 5.5 \\
\hline & & & Infarct & & & \\
\hline $30 \mathrm{~F}$ & 1pre-natal & 6/23/92 & 0.01 & 6.9 & 1 & 4 \\
\hline $31 \mathrm{M}$ & 1 post & $4 / 12 / 81$ & 3 & 9.5 & 2 & 4 \\
\hline $32 \mathrm{M}$ & 1post & 8/24/82 & 0.83 & 6.16 & 1 & 5 \\
\hline $33 \mathrm{M}$ & 1pre & 4/10/93 & 0.25 & 2.58 & 1 & 3 \\
\hline $34 \mathrm{~F}$ & 1pre & 7/17/93 & 0.02 & 1.25 & 2 & 0 \\
\hline $35 \mathrm{M}$ & 1pre & $8 / 30 / 80$ & 0.58 & 8.58 & 2 & 0 \\
\hline $36 \mathrm{~F}$ & 1pre & $6 / 3 / 83$ & 0.01 & 4 & 1 & 5 \\
\hline $37 \mathrm{M}$ & 1pre & $11 / 29 / 84$ & 0.5 & 9.75 & 1 & 6 \\
\hline $38 \mathrm{~F}$ & 1 post & 1/17/84 & 1.5 & 6.75 & 1 & 5 \\
\hline $39 \mathrm{~F}$ & 2 pre & $11 / 1 / 88$ & 0.33 & 0.83 & 2 & 0 \\
\hline $40 \mathrm{M}$ & 2 post & $4 / 8 / 82$ & 4 & 7.75 & 2 & 5 \\
\hline $41 \mathrm{M}$ & 2 post & $4 / 18 / 85$ & 0.6 & 2.18 & 1 & 6 \\
\hline $42 \mathrm{~F}$ & 2 pre & $6 / 14 / 87$ & 1.2 & 4.25 & 1 & 4 \\
\hline $43 \mathrm{~F}$ & 2pre & $11 / 11 / 83$ & 0.16 & 5.08 & 2 & 5 \\
\hline
\end{tabular}




\section{References}

Bates, E. (1999a). Plasticity, localization, and language development. In S. H. Broman \& J. M. Fletcher (Eds.), The Changing Nervous System (pp. 214 - 253). New York: Oxford University Press.

Bates, E., Vicari, S., and Trauner, D. (1999b). Neural mediation of language development: Perspectives from lesion studies of infants and children. In H. Tager-Flusberg (Ed.), Neurodevelopmental Disorders (pp. 533 - 582). Cambridge, MA: The MIT Press.

Boatman, D., Freeman, J., Vining, E., Pulsifer, M., Miglioretti, D., Minahan, R., Carson, B., Brandt, J., and McKhann, G. (1999). Language recovery after left hemispherectomy in children with late-onset seizures. Annals of Neurology, 46(4), 579 - 586.

Brown, R. (1973). A first Language. Cambridge, MA: Harvard University Press.

Caplan, R., Guthrie, D., Fish, B., Tanguay, P. E., and David-Lando, G. (1989). The Kiddie Formal Thought Disorder Rating Scale, (K-FTDS). Clinical assessment, reliability, and validity. Journal of the American Academy of Child and Adolescent Psychiatry, 28, 208-216.

Cohen, H. and Le Normand, M. T. (1998). Language development in children with simple-partial left hemisphere epilepsy. Brain and Language, 64, 409 - 422.

Cohen, M. (1992). Auditory/verbal and visual/spatial memory in children with complex partial epilepsy of temporal lobe origin. Brain and Language, 20, 315-326.

Curtiss, S. and de Bode, S. (1999b). Age and etiology as predictors of language outcome following hemispherectomy. Developmental Neuroscience, 21, 174 - 181.

Day, P. and Ulatowska, H. (1979). Perceptual, cognitive, and linguistic development after early hemispherectomy: two case studies. Brain and Language, 10, 287-317. 
de Bode, S. (1998). Interhemispheric language transfer and functional plasticity. In A. Greenhill, M. Hughes, H. Littlefield, \& H. Walsh (Eds.), Proceedings of the 22nd Boston University Conference on Language Development (Vol.1). Boston: Cascadilla Press.

de Bode, S. (2001). Predicting Language Outcomes after Hemispherectomy. Unpublished Dissertation, UCLA, Los Angeles.

de Bode, S. and Curtiss, S. (2000). Clinical variables predicting linguistic outcomes posthemispherectomy. in preparation.

Dennis, M. (1976). Impaired sensory and motor differentiation with corpus callosum agenesis: a lack of callosal inhibition during ontogeny? Neuropsychologia, 14, 455-469.

Dennis, M. (1980a). Capacity and strategy for syntactic comprehension after left or right hemidecortication. Brain and Language, 10, 287-317.

Dennis, M. (1980b). Language acquisition in a single hemisphere: semantic organization. In D. Caplan (Ed.), Biological Studies of Mental Processes (pp. 159-185). Cambridge, MA: MIT Press.

Dennis, M. (1988). Language and the young damaged brain. In T. Boll \& B. K. Bryant (Eds.), Clinical Neuropsychology and Brain Function: Research, Measurement, and Practice. . Washington, DC: APA.

Dennis, M. and Kohn, B. (1975). Comprehension of syntax in infantile hemiplegics after cerebral hemidecortication: left hemisphere superiority. Brain and Language, 2(4), 472-482.

Dennis, M. and Whitaker, H. (1976). Language acquisition following hemidecortication: linguistic superiority of the left over the right hemisphere. Brain and Language, 3, 404-433. 
Dravet, C., Guerrini, R., Mancini, J., Saltarelli, A., Livet, M. O., and Galland, M. C. (1996). Different outcomes of epilepsy due to cortical dysplastic lesions. In R. e. a. Guerrini (Ed.), Dysplasias of Cerebral Cortex and Epilepsy. Philadelphia: Lippincott-Raven Publishers.

Duchowny, M., Jayakar, P., Harvey, A. S., Resnick, T., Alvarez, L., Dean, P., and Levin, B. (1996). Language cortex represantation: effects of developmental versus acquired pathology. Annals of Neurology, 40(1), 31-38.

Dulac, O., Pinard, J. M., and Plouin, P.(1996). Infantile spasms associated with cortical dysplasia and tuberous sclerosis. In R. G. e. al. (Ed.), Dysplasias of Cerebral Cortex and Epilepsy . Philadelphia: Lippincott-Raven Publishers.

Eisele, J. A. and Aram, D. M. (1995). Lexical and grammatical development in children with early hemispheric damage: A cross-sectional view from birth to adolescence. In P. Fletcher \& B. MacWhinney (Eds.), The Handbook of Child Language (pp. 664-691). Cambridge: Blackwell Inc.

Fenson, L., Dale, P., Reznick, S., Bates, E., Thal, D., Reilley, J., and Hartung, I. (1990). MacArthur Communicative Development Inventories. Technical Manual. . San Diego: San Diego State University.

Gott, P., (1973). Language after dominant hemispherectomy. Journal of Neurology and Neurosurgical Psychiatry, 36, 1082-1088.

Grande, L. J. and al., e. (1998). Neuropsychological performance after anterior temporal lobectomy: do seizure-free patients really do better? Epilepsia, 39(6), 253.

Griffith, H. and Davidson, M. (1966). Long-term changes in intellect and behaviour after hemispherectomy. Journal of Neurology, Neurosurgery and Psychiatry, 29(6), 571-576. 
Helmstaedter, C., Kurthen, M., Linke, D. B., and Elger, C. E. (1994). Right hemisphere restitution of language and memory functions in right hemisphere language-dominant patients with left temporal lobe epilepsy. Brain, 117, 729-737.

Hoekstra, T. and Hyams, N. (1998). Aspects of root infinitives. Lingua, 106, 81-112.

Holthausen, H. e. a. (1998). Seizures post hemispherectomy. In I. Tuxhorn, H. Holthausen, \& H. Boenigk (Eds.), Paediatric Epilepsy Syndromes and Their Surgical Treatment (pp. 749 - 773). London: John Libbey.

Hyams, N. (1996). The underspecification of functional categories in early grammar. In H. Clahsen (Ed.), Generative Perspectives on language Acquisition (Vol. 14, pp. 91-127). Amsterdam: J. Benjamins Publishing Company.

Isaacs, E., Chrisie, D., Vargha-Khadem, F., and Mishkin, M. (1996). Effects of hemispheric side of injury, age at injury, and presence of seizure disorder on functional ear and hand asymmetries in hemiplegic children. Neuropsychologia, 34(2), 127-137.

Kennard, M. (1940). Relation of age to motor impairments in man and subhuman primates. Archives of Neurology and Psychiatry, 44, 377-397.

Kolb, B. (1990). Sparing and recovery of function. In B. Kolb \& R. Tees (Eds.), Cerebral Cortex of the Rat (pp. 537-562). Boston: MIT Press.

Krynouw, R. A. (1950). Infantile hemiplegia treated by removing one cerebral hemisphere. Journal of Neurology, Neurosurgery and Psychiatry, 13, 243.

Levy, Y. and Kave, G. (1999). Language breakdown and linguistic theory: a tutorial overview. Lingua, 107, 95-143. 
Mariotti, P., Iuvone, L., Torrioli, M. G., and Silveri, M. C. (1998). Linguistic and non-linguistic abilities in a patient with early left hemispherectomy. Neuropsychologia, 36(12), 1303-1312.

Mathern, G. W., Giza, C. C., Yudovin, S., Vinters, H. V., Peacock, W. J., Shewmon, D. A., and Shields, W. D. (1999). Postoperative seizure control and antiepileptic drug use in pediatric epilepsy surgery patients: the UCLA experience, 1986 - 1997. Epilepsia, 40(12), 1740-1749.

McFie, J. (1961). The effects of hemispherectomy on intellectual functioning in cases of infantile hemiplegia. Journal of Neurology, Neurosurgery and Psychiatry, 24, 240-249.

Metz-Lutz, M. N., Kleitz, C., de Saint Matrin, A., Massa, R., Hirsch, E., and Marescauz, C. (1999). Cognitive development in benign focal epilepsies of childhood. Developmental Neuroscience, 21 , 182-190.

Muter, V., Taylor, S., and Vargha-Khadem, F. (1997). A longitudinal study of early intellectual development in hemiplegic children. Neuropsychologia, 35(3), 289-298.

Ogden, J. (1996). Phonological dyslexia and phonological dysgraphia following left and right hemispherectomy. Neuropsychologia, 34(9), 905-918.

Ogden, J. A. (1988). Language and memory functions after long recovery periods in lefthemispherectomized subjects. Neuropsychologia, 26(5), 654-659.

O'Leary, D. S., Lovell, M. R., Sackellares, J. C., Berent, S., Giordani, B., Seidenberg, M., Boll, T. J. (1983). Effects of age of onset of partial and generalized seizures on neuropsychological performance in children. The Journal of Neurvous and Mental Disease, 171(10), 624-629.

Papanicolaou, A., DiScenna, A., Gillespie, L., and Aram, D. (1990). Probe-evoked potential findings following unilateral left-hemisphere lesions in children. Archives of Neurology, 47, 562-566. 
Paquier, P. F. and Van Dongen, H. R. (1998). Is acquired childhood aphasia atypical? In P. Coppens, Y. Lebrun, \& A. Bassp (Eds.), Aphasia in Atypical Populations (pp. 67-117). New Jersey: Lawrence Erlbaum.

Peacock, W. J., Wehby-Grant, M. C., Shields, W. D., Shewmon, D. A., Chugani, H. T., Sankar, R., and Vinters, H. V. (1996). Hemispherectomy for intractable seizures in children: a report of 58 cases. Child's Nervous System( 12), 376-384.

Rausch, R., Boone, K., and Ary, C. M. (1991). Right hemisphere language dominance in temporal lobe epilepsy: clinical and neuropsychological correlates. Journal of Clinical and Experimental Neuropsychology, 13( 2), 217-231.

Reilly, J., Bates, E., and Marchman, V. (1998). Narrative discourse in children with early focal brain injury. Brain and Language, 64(3), 335-376.

Riva, D. and Gazzaniga, L. (1986). Late effects of unilateral brain lesions before and after the first year of life. Neuropsychologia, 24, 423-428.

Rossi, P. G., Parmeggiani, A., Santucci, M., Baioni, E., Amadi, A., and Berloffa, S. (1996). Neuropsychological and pshychiatric findings in cerebral cortex dysplasias. In R. Guerrini \& e. al. (Eds.), Dysplasias of Cerebral Cortex and Epilepsy . Philadelphia: Lippincott-Raven Publishers.

Seidel, W. T., Lin, M. I., Snead, O. C., and Chen, L. S. (1998). Is seizure relief related to cognitive outcome in children? Epilepsia, 39 Suppl. 6, 174.

Smith, A. and Sugar, O. (1975). Development of above normal language and intelligence 21 years after left hemispherectomy. Neurology, 25(9), 813-818.

Stark, R. E., Bleile, K., Brandt, J., Freeman, J., and Vining, E. P. (1995). Speech-language outcomes of hemispherectomy in children and young adults. Brain and Language, 51, 406-421. 
Stark, R. E. and McGregor, K. K. (1997). Follow-up study of a right- and a left-hemispherectomized child: implications for localization and impairment of language in children. Brain and Language, $60(2), 222-242$.

Teuber, H. L. (1975). Recovery of function after brain injury in man. Paper presented at the Ciba foundation Symposium, 34. Outcome of severe damage to the central nervous system, Amsterdam.

Vargha-Khadem, F., Isaacs, E. B., Papaleloudu, H., Polkey, C. E., and Wilson, J. (1991). Development of language in six hemispherectomized patients. Brain, 114, 473-495.

Vargha-Khadem, F. (1993). Congenital versus acquired insult of the cerebral hemispheres: neuropsychological perspectives. Educational and Child Psychology, 10( 1), 12-16.

Vargha-Khadem, F., Carr, L. J., Isaacs, E., Brett, E., Adams, C., and Mishkin, M. (1997a). Onset of speech after left hemispherectomy in a nine-year-old boy. Brain, 120, 159-182.

Vargha-Khadem, F. and Mishkin, M. (1997b). Speech and language outcome after hemispherectomy in childhood. In I. Tuxhorn, H. Holthausen, \& H. Boenigk (Eds.), Paediatric epilepsy syndromes and their surgical treatment (pp. 774-784). London: John Libbey.

Vargha-Khadem, F. and Polkey, C. E. (1992). Review of cognitive outcome after hemidecortication in humans. In F. D. Rose \& D. A. Johnson (Eds.), Recovery From Brain Damage (pp. 137-151). New York: Plenum Press.

Verity, C. M., Strauss, E. H., Moyes, P. D., Wada, J. A., Dunn, H. G., and Lapointe, J. S. (1982). Long-term follow-up after cerebral hemispherectomy: neurophysiologic, radiologic, and psychological findings. Neurology, 32, 629-639. 
Villablanca, J. R., Carlson-Kuhta, P., Schmanke, T. D., and Hovda, D. A. (1998). A critical maturational period of reduced brain vulnerability to developmental injury. I. Behavioral studies in cats. Developmental Brain Research, 105, 309-324.

Villablanca, J. R. and Hovda, D. A. (2000). Developmental neuroplasticity in a model of cerebral hemisphetectomy and stroke. Neuroscience, 95(3), 625 - 637.

Wilson, P. J. (1970). Cerebral hemispherectomy for infantile hemiplegia: A report of 50 cases. Brain: A Journal of Neurology, 93(1), 147-180.

Woods, B. T. and Teuber, H. L. (1978). Changing patterns of childhood aphasia. Annals of Neurology, 3, 273-280. 